\title{
Composite building structures and their fire resistance: a methodology of resource-saving evaluation
}

\author{
Nikolay Ilyin ${ }^{1}$, Denis Panfilov, ${ }^{1, *}$, and Evgeniy Zaslavsky ${ }^{1}$ \\ ${ }^{1}$ Samara State Technical University, Institute of Architecture and Civil Engineering, 194, \\ Molodogvardeyskaya St., Samara, 443001, Russia
}

\begin{abstract}
The paper presents a new resource-saving methodology of determining design fire resistance of composite (steel reinforced-concrete) building constructions. The suggested methodology establishes indicators of fire safety of a building which consist in ensured duration of a steel corrugated wall resistance and of tension and compression composite flange of reinforced concrete building structure in terms of standard heating tests; as well as in the assessment of designed limits of fire resistance of a composite building structure during its design-stage, construction or maintenance of the building; and also in for of fire resistance. The paper introduces an improved algorithm for solving firetechnical tasks in respect to express-calculation of designed fire resistance of composite building structures. The article provides results of a scientific research and the content of its technical effect including resource saving while putting into practice an innovative solution of fire protection and ensure fire-resistance of buildings constructions. The results of this scientific research are recommended for practical application in design organizations and can be used to improve existing regulatory documents for fire safety.
\end{abstract}

\section{Introduction}

The innovative solution here refers to the field of fire safety of buildings and constructions (hereinafter "buildings") and can be used for effective classification of composite building structures according to indicators of their resistance to high temperature effects $(1000 \pm$ 150) ${ }^{0} \mathrm{C}$. This justifies the use of composite constructions (steel reinforced-concrete) with designed limits of fire resistance in buildings of different functional classes by flammability classification.

The relevance of measuring indicators of fire resistance of composite building structures becomes evident during the process of renovating buildings, strengthening their parts and elements, bringing fire-resistance in accordance with the requirements of modern construction standards, during the examination and restoration of composite structures, damaged by fire $[1,2]$.

*Corresponding author: panda-w800i@yandex.ru 


\section{Materials and Methods}

The most famous methods of evaluating elements of a composite building structure are implemented by using field tests and include a technical examination, determination of the size of a cross-section and reinforced concrete composite elements, setting the depth of coverage of the working valve and the extent of its fire-proof capability and determination of thermal parameters. The next step is to define fire-resistance indicators of each element of the composite construction for the duration of high temperature resistance up to a loss of load capacity by the least fire-resistant composite construction element [3]. However, this methodology is usually applied to the elements of a composite construction, that represents only tension and compression flanges, without a fire-resistance test of a corrugated-wall of this composite construction.

The suggested methodology establishes indicators of fire safety of a building which consist in ensured duration of a steel corrugated wall resistance and of tension and compression composite flange of reinforced concrete building structure in terms of standard heating tests; as well as in the assessment of designed limits of fire resistance of a composite building structure during its design-stage, construction or maintenance of the building; and also in for of fire resistance $[4,5]$.

\section{Results}

A technological effect of using the proposed methodology of problem solving consists in the fact that fire resistance of the elements of the composite construction is assessed without field tests by non-destructive testing; technical inspection is supported by instrumental measurement of geometrical sizes of the composite construction; the depth of coverage, the heating conditions and the degree of-fire protection are determined by mortar of checkpoint of corrugated walls and working reinforcement of tension and compression reinforced concrete flanges of the composite structure, thermal and structural parameters are calculated, and by using them, the value of designed limits of fire resistance of the composite building structure $F_{u r}$ for the duration of high temperature resistance up to a loss of load capacity by the least fire-resistant composite construction element $f_{u r \text {,min }}$ of the composite construction by condition (1):

$$
F_{u r}=f_{u r, \min } .
$$

The duration of the resistance from the beginning of the standard heating up to a loss of load capacity of a reinforced concrete tension flange of a composite structure $\left(f_{u r l}, \mathrm{~min}\right)$, is determined by using an analytic equation (2):

$$
f_{u r, 1}=\left(2,15 \cdot\left|\ln J_{\sigma r}\right|\right)^{6,6 / n} \cdot e^{c} \cdot K_{1} /\left(425 / t_{c r}\right)^{6,6} ;
$$

where $J_{\sigma s}$ is the intensity of strength stress in the longitudinal working reinforcement of the tension flange $(0.1 \div 1.0) ; \quad C$ is the degree of fire protection of concrete working reinforcement, $\mathrm{cm} ; n$ is an empirical index of changes in properties of reinforcement steel in conditions of a thermal test; $t_{c r}$ is critical temperature for reinforcing steel, ${ }^{0} C[4,6]$.

The intensity of strength stress in the longitudinal working reinforcement of a tension flange of the composite construction coming from a test load for fire-poof capacity, is calculated by the equation (3):

$$
J_{\sigma 3,1}=\left(A_{s, m p} / A_{s}\right) \cdot\left(R_{s} / R_{s u}\right) \cdot\left(N_{g} / N\right) \leq 1
$$


where $A_{s}$ and $A_{s, m p}$ are reinforcement area actually installed in the section of the tension flange (which is required by strength calculation), $\mathcal{M M}^{2} ; R_{s} и R_{s u}$ - are estimated and ultimate resistance of tensile reinforcement, $M P a,\left(R_{s u}=R_{s n} / 0,9\right) ; N$ and $N_{\rho}$ are estimated axial force and effort from the test load for fire-resistance capacity, $k N[7,12]$.

The stress of the test load in the tension flange of the composite construction is determined from the expression (4):

$$
N_{p}=N_{\partial л} / \gamma_{f m}
$$

where $N_{l n}$ is the long-term part of the design load, $k N ; \gamma_{f m}$ is a load safety coefficient [7, 12].

The degree of fire protection of the longitudinal working reinforcement of the tension flange of a composite construction, is determined by using the equation (5):

$$
C=1,44 \cdot m_{0} \cdot a_{\min } / D_{B m}^{0,8} ;
$$

where $m_{0}$ is an index of heating conditions in the section of a tension flange $(0.25-1.0) ; a_{\min }$ is the minimum depth of reinforcement depth of coverage along the coordinate axis, $\mathrm{mm}$; $D_{b m}$ is an index of thermal diffusion rate of the protective layer of concrete, $\mathrm{MM}^{2} / \mathrm{min}^{\text {[7] }}$.

When reinforcement bars are unsymmetrical to the bisector of an angle of the rectangular cross sections of reinforced concrete composite construction, the index of heating conditions of reinforcement $\left(m_{0}\right)$ in conditions of double faced heating $\left.a_{x} \leq a_{y}\right)$ is defined by using the demonstrative function (6):

$$
m_{0}=0,5 \cdot\left(a_{y} / a_{x}\right)^{0,5} \leq 1
$$

where $a_{x}$ and $a_{y}$ are the coverage depth of reinforcement bars from the heated faces of the element at the coordinate axis of cross-sections, мм; (with $a_{x}>a_{y}-$ in Function (6), the inverse of the ratio of the magnitude of the axial distances, $\left.a_{x} / a_{y}\right)[4,7]$.

Depth of coverage of working reinforcement bars on the coordinate axes (axial distances $\mathrm{a}_{\mathrm{x}, \mathrm{y}}$ ) are calculated by using the equation (7):

$$
a_{x, y}=u_{x, y}+0,5 \cdot d_{s}
$$

where $a_{x, y}$ is the thickness of protective layers, respectively along $x$ or $y$ axis, $\mathcal{M M}_{\mathrm{A}}$ is a nominal diameter of longitudinal reinforcement bars, $\mathrm{mm}[7,12]$.

The amount of thermal diffusion index of concrete protective layer $\left(D_{6 m}, \mathrm{~mm}^{2} / \mathrm{min}\right)$ with average temperature of $450^{\circ} \mathrm{C}$, is determined by using an analytic equation (8):

$$
D_{\text {sm }}=60 \cdot 10^{3} \cdot\left(\lambda_{0} \pm 0,45 \cdot b\right) /\left[p_{c} \cdot\left(C_{0}+0,45 \cdot d+\omega / 20\right)\right]
$$

where $\lambda_{0} \boldsymbol{}{ }_{0}$ are indexes of concrete thermal conductivity, $w /(m \cdot C)$, and specific thermal capacity, $\mathrm{kJ} /(\mathrm{kg} \cdot \mathrm{C})$, at normal temperature $\left(20 \pm 5^{\circ} \mathrm{C}\right) ; b$ and $d$ are thermal coefficients of thermal conductivity and heat capacity of concrete; $p_{c} u \omega$ are density of concrete in dry condition, $\mathrm{kg} / \mathrm{m}^{3}$, and its moisture content, \% by mass [4].

The integrated index of concrete tension flange safety of a composite construction is defined by using the equation (9):

$$
K_{1}=\gamma_{n} \cdot m_{\text {об }} \cdot k_{c n} \cdot k_{\phi}
$$

where $\gamma_{n}$ is the coefficient of tension flange reliability by the building designation; $m_{o \sigma}$ is an index of perimeter heating conditions of the section of a composite construction; $k_{c n}$ is an index of continuity of the section of composite construction; $k_{\phi}$ - an index of nominal diameter of working reinforcement [7]. 
The duration of the resistance of a reinforced concrete tension flange of a composite structure $f_{u r, 2}, \mathbf{M u H}$ from the beginning of the standard heating up to a loss of load capacity, is determined by using an analytic equation (10):

$$
f_{u r, 2}=5 \cdot B^{2} \cdot\left(1-J_{\sigma o}\right)^{2} \cdot\left(1-0,6 \cdot \alpha_{\mu 3}\right) \cdot K_{2} /\left(D_{B m}^{2} \cdot R_{B n}^{0,25}\right) ;
$$

where $\mathrm{B}$ is the smallest size of rectangular cross sections in a compression flange, $\mathrm{mm} ; \mathrm{J}_{\sigma 0}$ is an intensity of strength stress in the cross section of a compression flange $(0-1) ; \alpha_{\mu 3}$ is a degree of reinforcement of a compression flange; $K_{2}$ is an integral index of safety of a compression flange; $D_{b m}$ is thermal diffusion rate of the protective layer of concrete, $\mathrm{mm}^{2} / \mathrm{min} ; R_{b n}$ is normative strength of concrete for resistance to axial compression, $\operatorname{MPa}[7,12,13]$.

The intensity of strength stress in the cross-section of the compression flange of the composite construction $\left(J_{\sigma 0}\right)$ coming from a test load for fire-poof capacity, is calculated by conditions (11):

$$
J_{\sigma o}=k_{3} \cdot N_{\rho o} / N_{u n} ;
$$

where $k_{3}$ is the coefficient of fixing conditions of the compression flange $(0,8-0,9)$; $N_{\rho 0}$ - is a test load when evaluating fire resistance of rhw compression flange, $\kappa H$; $N_{u n}$ is an axial force breaking the compression flange even before thermal tests, $k N[7,12]$.

The degree of reinforcement of the compression flange $\left(\alpha_{\mu 3}\right)$ is calculated by the expression (12):

$$
\alpha_{\mu 3}=\left(A_{s} / A\right) \cdot\left(R_{s c} / R_{B n}\right)
$$

where $A_{s} \mathrm{U} A$ are respectively reinforcement area and the concrete area in the cross section of a compression flange, $\mathrm{mm}^{2} ; R_{s} u R_{b n}$ are respectively estimated resistance of tensile reinforcement and ultimate resistance of concrete to axial compression, $M p a$ [7].

The integrated index of concrete compression flange safety $\left(K_{2}\right)$ is defined by using the algebraic equation (13):

$$
K_{2}=\gamma_{n} \cdot m_{\text {об }} \cdot k_{c n} \cdot k_{a} \cdot \varphi
$$

where $\gamma_{n}$ is the coefficient of the composite building structure reliability by the building designation; $m_{o \sigma}$ is an index of perimeter heating conditions of the section of a composite construction; $k_{c n}$ is an index of continuity of the section of composite construction; $k_{a}$ - an index of depth of coverage of working reinforcement; $\varphi$ is a coefficient of longitudinal bending of a compression flange [7].

The duration of the resistance of a steel corrugated-wall $f_{u r, 3}$, min with account of fire protection, is calculated by the equation (14):

$$
f_{u r, 3}=48 \cdot\left(1-J_{o s, 3}\right)^{3} \cdot e^{c}+r_{u s, c n}
$$

where $J_{o s} \mathrm{~s}$ an intensity of strength stresses in the steel of corrugated wall $(0.1 \pm 0.05)[8,9]$.

Degree of fire protection of the steel of corrugated wall is found by using the equation (15):

$$
C=1,45 \cdot m_{0} \cdot \delta_{0} / D_{6 m}^{0,8}
$$

where $m_{0}$ is an indicator of heating conditions of the checkpoint of steel corrugated wall during symmetrical double-faced heating: $m_{0}=0,5 ; \delta_{0}$ is the thickness of fire-proof coating 
of a corrugated wall, $\mathrm{mm} ; D_{b m}$ is the index of thermal diffusion of coating material, $\mathrm{mm}^{2} / \mathrm{min}[10,11]$.

The duration of the resistance of a steel corrugated-wall without fire protection $r_{u s, c m}$, is calculated by the analytical equation (16):

$$
r_{u s, c m}=6 \cdot\left\{\left(A_{s, c m} / p_{01}\right)+18,33 \cdot\left[\left(1-J_{\sigma s, c m}\right)^{1 / 2}-0,5\right]\right\} ;
$$

where $A_{s, c m}$ is the area of the steel section of the corrugated wall $\mathrm{cm}^{2} ; p_{01}$ is the heating perimeter of the section of the corrugated wall, $\mathrm{cm} ; J_{\sigma s, \mathrm{~cm}}$ is the intensity of strength stress in the cross section of the corrugated wall $(0.1 \pm 0.05)[8,9]$.

Figure 1 presents a geometric diagram of a composite construction with parallel flanges.

Figures 2 and 3 show a design model of a reinforced concrete compression/tension flange of a composite structure to the determination of bearing capacity of (a) and to the evaluation of fire resistance (b).

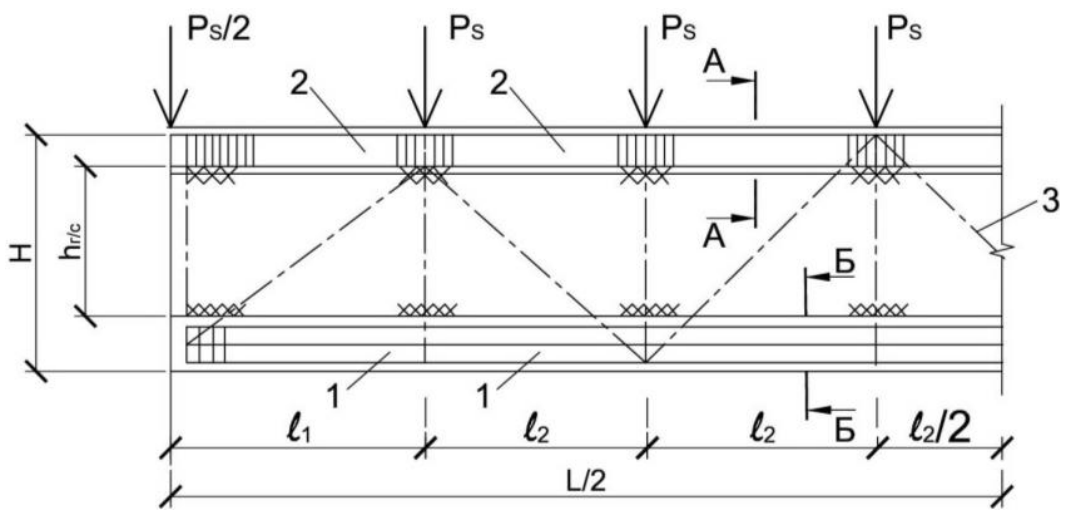

Fig. 1.Geometric diagram of a composite construction with parallel flanges. 1 - lower reinforced concrete flange; 2 - upper reinforced concrete flange; 3 - steel corrugated wall; $h_{2} / c$ - corrugated wall height; $H$ height of a composite construction; $P_{s}-$ load

$$
\text { A - A }
$$

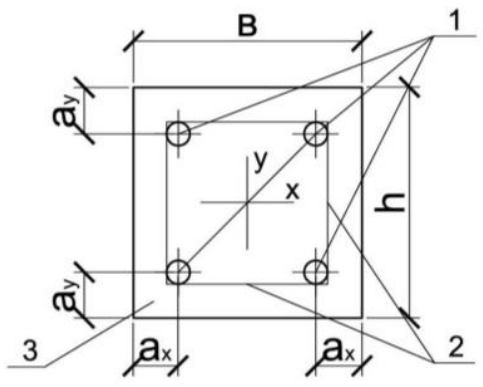

a)

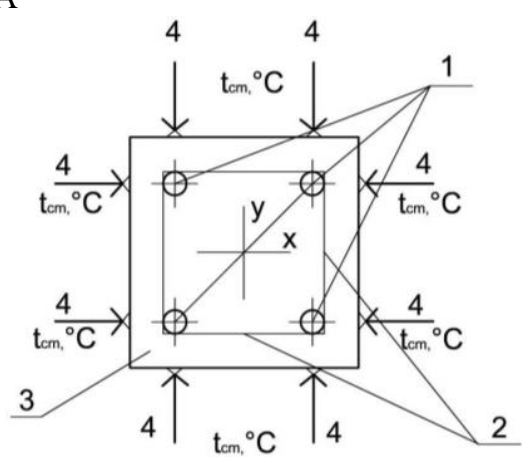

b)

Fig. 2. A design model of a reinforced concrete compression flange (cross-section A-A) to strength estimation (a); to fire resistance capacity of an element (b): 1 - working compressed reinforcement; 2 - clamps; 3 - concrete protective layer; 4 - direction of heating, tst, ${ }^{\circ} \mathrm{C}$.

Thermal diffusion rate of protective material $\left(D_{b m}, \mathrm{MM}^{2} / \mathrm{min}\right)$ is calculated by using the analytic equation (17): 


$$
D_{b m}=\frac{60 \cdot 10^{3} \cdot\left(\lambda_{0} \pm b \cdot 10^{-3} \cdot t_{m}\right)}{\rho_{c} \cdot\left(C_{0}+d \cdot 10^{-3} \cdot t_{m}+0,05 \cdot w\right)}
$$

where $\lambda_{o} \mathbf{n} b$ - are empirical numbers to calculate the thermal conductivity coefficient of heated material $w /\left(m \bullet{ }^{\circ} \mathrm{c}\right) ; t_{m}$ - average temperature of the material along the section of the element $\left(450^{\circ} \mathrm{C}\right) ; C_{o}$ иd - are empirical numbers to calculate the specific thermal capacity of the heated material $\mathrm{kJ} /\left(\mathrm{kg} \cdot{ }^{\circ} \mathrm{C}\right) ; \mathrm{w}$ - is humidity of material mass, $\% ; \rho_{s}$ is average density of dry material, $\mathrm{kg} / \mathrm{m}^{3}$.

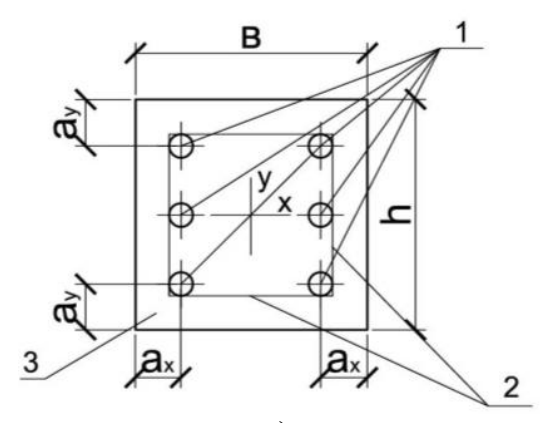

a)

$$
\text { B - B }
$$

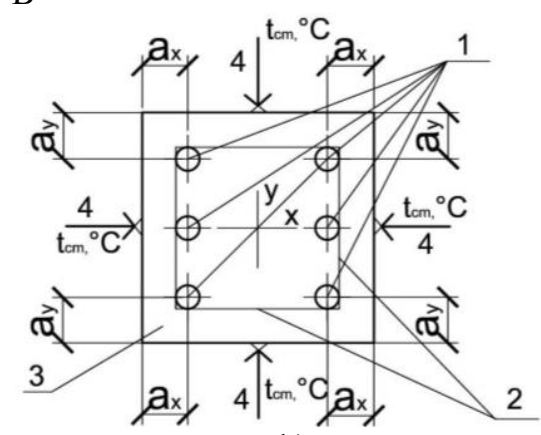

b)

Fig. 3. A design model of a reinforced concrete tension flange (cross-section B-B) to strength estimation (a); to fire resistance capacity of an element (b): 1 - working tensile reinforcement; 2 clamps; 3 - concrete protective layer; 4 - direction of heating, $\mathrm{t}_{\mathrm{cm}},{ }^{\circ} \mathrm{C}$.

On the basis of the mathematical description of the resistance process of building structures exposed to external load and high temperature the researchers obtained calculation formulas for evaluating fire resistance of steel deflected reinforced concrete elements.

To estimate fire resistance of steel reinforced deflected concrete elements $F_{u(R)}$, $\min$, reinforced by steel of different classes, the estimated equation has the form (18):

$$
F_{u r}=\left(2,15 \cdot \ln J_{\sigma s} l\right)^{6,6 / n} \cdot\left(t_{c r} / 425\right)^{6,6} \cdot e^{c} \cdot\left(d_{s} / 10\right)^{0,05}, \text { min; }
$$

where $J_{\sigma \bar{\sigma}}$ is an intensity of stresses in working reinforcement $\left(J_{0}=1 / K_{\tilde{\sigma}}\right.$; here $K_{\sigma}$ is the indicator of bearing capacity stockage of deflections prior to the fire test); $t_{c r}$ - critical temperature, ${ }^{o} C ; n$-empirical coefficients of different types of reinforcing steel.

Integral degree of fire protection of the working reinforcement, $\mathrm{cm}$ :

$$
\begin{gathered}
C=0,12 \cdot C_{\text {озс }}=1,44 \cdot m_{o} \cdot a_{\min } / D_{b m}^{0,8} ; \\
C_{\text {озс }}=12 \cdot m_{o} \cdot a_{\min } / D_{b m}^{0,8} ;
\end{gathered}
$$

where $a_{\min }$ is a minimum axial distance to the center of reinforcement, $m m ; m_{o}$ an index, taking into account the location of reinforcement in the section of the element and conditions of its heating; $D_{b m}$ is a thermal diffusion rate of concrete, $\mathrm{mm}^{2} / \mathrm{min}$.

Index, taking into account design characteristics of the element:

$$
k=k_{0} \cdot k_{m} k_{s}
$$

where $k_{0}$ is an index taking into account the influence of voidness of the cross-section for fire resisting property of the element: (for a solid section -1 ; for a hollow flooring -0.8 );

$k_{s}$ is an index taking into account the value of diameter $\mathrm{d}, \mathrm{mm}$, of working reinforcement for the limit of fire resistance: 


$$
k_{s}=(0,1 \cdot d)^{0,05}
$$

where $k_{m}$ is the index of working conditions of a continuous structure

$$
k_{m}=1+0,5 \cdot\left(A_{o p} / A\right)^{1,5}
$$

where $A_{o p}$ and $A$ are respectively the cross-section of the working reinforcement on is supporting structure and in the span; for a simple beam construction $\mathrm{km}=1$.

A technological effect of using the proposed methodology of fire resistance of a composite construction is achieved because of the extended range of application of the evaluating method of fire resistance of building structures with a different kind of stress state of elements of the integral design of the building; the approximation of test conditions of the elements of composite structures to real conditions of these structures operation and use; the improved accuracy of test results because of the use of a statistical method for the evaluation of single parameters of quality elements of composite construction; the designation of a set of core parameters affecting fire resistance of the elements of composite constructions; calculation of integral parameters of thermal and structural characteristics of elements in composite constructions; compilation of mathematical models (descriptions) of resistance process of the elements of composite constructions by standard fire tests. A mathematical description of the resistance process of a composite steel reinforced-concrete construction to a non-stationary effect of high temperatures is an effective means of assessing designed fire-resistance capacity according to a loss of load bearing capacity.

\section{Conclusions}

The research suggests a mathematical description of the resistance process of composite steel building constructions to the heating effect of a standard fire. Analytical equations of this mathematical description serve as a basis for the express algorithm of calculating designed fire resistance properties of steel reinforced-concrete structures.

The value of designed limits of fire resistance of a steel reinforced-concrete construction is determined by a loss of load capacity of the least fire-resistant composite construction element: steel corrugated walls, compression or tension concrete flanges. With account of a permissible error in the results, this mathematical calculation model of equations that describe the process of resistance of composite structures to heat effects is relatively simple and convenient for computer programming.

The paper also puts forward a new constructive form of a composite steel reinforcedconcrete building structure and an advanced system of actions for evaluating fire resistance of the elements at the level of inventions that are embedded into the construction practice $[3-6,13,14]$.

The express method of calculation makes it possible to pre-evaluate designed fire resistance of composite steel reinforced-concrete structures in the progressive stage of the building design. The results of this scientific research are recommended for practical application in design organizations and can be used to improve existing regulatory documents for fire safety.

\section{References}

1. P.Wang et al. Thin-Walled Structures 98, 29-38 (2016)

2. P. Zhai et al. IJIE 97, 29-45 (2016) 
3. N.A. Ilyin, D.A. Panfilov. Application for invention No a 2015136088 IPC G01 N 25/50 req. SGASU 25.08.2015

4. V.K.R. Kodur et al. Fire Safety Journal 45, 211-220 (2010)

5. N.A. Ilyin, A.A. Surgachev, V.V. Turnikov, S.V. Esmont. 2282848 Patent of the Russian Federation, MPK 7 G 01 N 25/50

6. N. Ilyin, S.Vedernikov. Patent №. 2320982 RU, G 01 N 25 MPC/50

7. N.A. Ilyin, D.A. Panfilov, STO SGASU 21.13.35-15 (2015)

8. V.A. Zubkov, A.O. Lukin, Vestnik MGSU 2, 37-46 (2013)

9. Lukin A.O, Building Mechanics and Structures Calculation 5, 10-17 (2013)

10. N.A. Ilyin. STO SGASU 21.13.34-16 (2016)

11. Russian Standard SP 16.13330. 2011

12. Russian Standard SP 63. 13330.2012

13. N.A. Ilyin, D.A. Panfilov, D.V. Litvinov, P.N. Slavkin, Urban Construction and Architecture 1, 82-89 (2015). DOI: 10.17673/Vestnik.2015.01.13

14. N.A. Ilyin,D.A. Panfilov,D.V. Litvinov, N.V. Tretyakov, Urban Construction and Architecture 3, 112-119 (2015). DOI: 10.17673/Vestnik.2015.03.15 